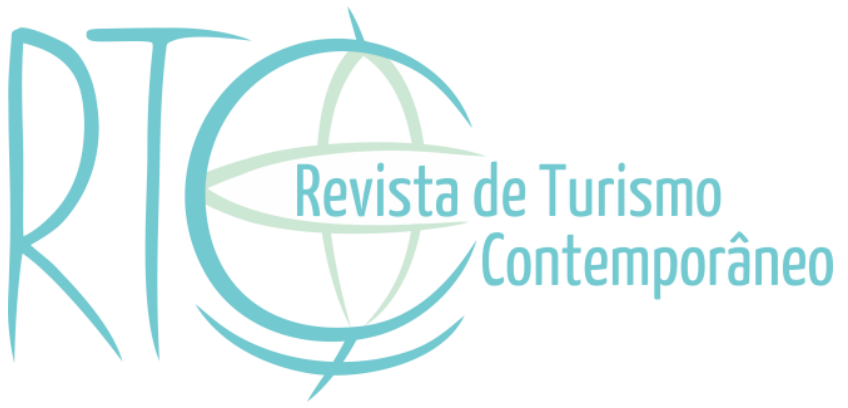

\title{
MICE Tourism (Meetings, Incentives, Conferencing and Exhibitions) como gerador de Turismo Interno: Analisando a cidade de Pelotas, RS
}

\author{
MICE Tourism (Meetings, Incentives, Conferencing and \\ Exhibitions) as generator of internal tourism: analysis of \\ Pelotas, RS city
}

\section{Adriana Fumi Chim-Miki}

Doutora do Programa Turismo, Economia e Gestão Faculdade de Economia, Empresa e Turismo da Universidad de Las Palmas de Gran Canaria, Espanha E-mail: adriana.chimmiki@gmail.com

\section{Adalberto dos Santos Júnior}

Professor da Universidade Federal de Pelotas-UFPEL. Pelotas/RS, Brasil E-mail: adalberto_jr@hotmail.com

\section{Christina Oliveira Matos}

Doutoranda do Programa Turismo, Economia e Gestão Faculdade de Economia, Empresa e Turismo da Universidad de Las Palmas de Gran Canaria, Espanha E-mail: matos_christina@hotmail.com Espanha. 


\section{RESUMO}

Este artigo apresenta as oportunidades do Turismo MICE Interno para as cidades consideradas regionais. Esta modalidade de turismo urbano, em termos mundiais e nacionais tem apresentado expressivo crescimento. Além disso, está sendo indicada como um produto complementar ou substituto ao clássico turismo de Sol e Praia, especialmente para destinos que estão apresentando sintomas da maturidade deste modelo, ou áreas em que não há condições naturais favoráveis a um completo desenvolvimento baseado em Sol e Praia. $\mathrm{O}$ objetivo primordial deste trabalho é contribuir com a literatura acadêmica, apresentando uma revisão conceitual e tipológica do turismo MICE, e revisão de atributos para destinos MICE. Secundariamente, se objetiva apresentar a cidade de Pelotas a partir dos determinantes de turismo MICE, analisando-a como candidata a Destino MICE Regional. A metodologia é qualitativa, sendo um estudo de caso que utiliza dados primários através de informação coletada nos sites de promoção turística oficiais do município. Conclui-se que a cidade de Pelotas, situada no sul do Estado do Rio Grande do Sul (RS), possui condições de tornar-se um Destino MICE Regional, porém se recomenda uma melhoria no planejamento turístico, em términos de focalizar no desenvolvimento dos atributos de competitividade MICE, e especialmente uma melhoria na qualidade e quantidade das informações sobre suas capacidades como Destino MICE.

Palavras-Chaves: Meeting Tourism; Atributos de Destino MICE; Turismo de reuniões, Cidade Regional; Competitividade Turística, Pelotas/RS.

\section{ABSTRACT}

This article presents the opportunities of Internal MICE Tourism as a kind of tourism for develops in regional cities. This type of urban tourism has grown significantly, in global and national level. It is being indicated as a complementary product or substitute to the classic sun and sand Tourism, especially for destination that are presenting symptoms of maturity of this model, or areas where there aren't natural conditions conducive to full development based on Sun and Sand Tourism. The primordial objective of this work was contribute to the academic literature, presenting a theoretical review of MICE tourism and its typologies, as well as, the attributes of MICE Destination. The second goal of this paper was analyses the Pelotas City according to MICE tourism determinants, considering it as a candidate to be a regional MICE destination. The methodology is qualitative, presents a case study, using primary data collected through information extracted of official sites to promotion tourism. We conclude that city of Pelotas, located in the south of State of Rio Grande do Sul (RS), has the resources to become a Regional MICE Destination. However, it is recommended an improvement in the tourism planning in terms to focus on competitiveness attributes to Meetings Tourism, and especially an improvement in the quality and quantity of information about its capacities as MICE Destination.

Keywords: Meeting Tourism; MICE Destination attributes; Regional City; Tourism competitiveness, Pelotas/RS. 


\section{INTRODUÇÃO}

A categoria classificada internacionalmente como MICE Tourism (Meetings, Incentives, Conferencing and Exhibitions), ou simplesmente por Meeting Tourism, ou ainda pelo setor MICE, tem apresentado importante crescimento em vários países e cidades (ChimMiki, Zuñiga-Collazos, Gandâra, \& Medina-Muñoz, 2013; Crouch \& Louviere, 2004; Crouch \& Ritchie, 1998;McCartney, 2008; Oppermann, 1996; Oppermann \& Chon, 1997; ; Ro \& Um, 2006; Weber \& Ladkin, 2005; Wong, 2011).

Por isto esta modalidade de turismo está recebendo muitas atenções por parte das políticas públicas e privadas que buscam inserir ações para incentivar seu desenvolvimento. $\mathrm{O}$ Brasil inclui no "Plano Aquarela 2020", a intenção de melhorar o ainda mais o desempenho neste setor, apesar de que nos últimos dois anos o país já ocupa a $7^{\mathrm{a}}$. posição Ministério do Turismo [MTur] ( 2012). Em termos mundiais, o número de eventos internacionais cresce em média de $10 \%$ por ano, tendo mantido seu crescimento mesmo no período de crise econômica mundial, International Congress and Convention Association [ICCA] (2013). Especificamente o Brasil apresentou um crescimento exponencial e se mantem nos últimos nove anos, como figura constante entre os 10 países que mais recebem eventos internacionais ICCA ( 2013).

Ainda que esteja no foco das atenções, o segmento ainda tem muito que evoluir em termos de pesquisas acadêmicas, havendo uma falta de nitidez sobre o que inclui o setor MICE, sobre sua vinculação com o turismo de eventos e com o turismo urbano, e especialmente sobre quais os determinantes/critérios necessários para que uma cidade se consagre como um destino MICE. Alguns autores salientam que faz pouco tempo que esta temática passou a ser estudada desde a perspectiva do turismo urbano (Abbey \& Link, 1994; Choi \& Boger, 1998; Dwyer, 1999; Dwyer, Mistilis, Forsyth, \& Prasada 2001; Go \& Zhang, 1997; Mair, \& Jago, 2010; Mistilis \& Dwyer, 1999; Oppermann, 1994; Ro \& Um, 2006; Webber, 2001; Wong, 2011 Zelinsky, 1994).

Os países e cidades habitualmente utilizam os indicadores que mostram a evolução em nível de eventos internacionais a partir dos dados de ICCA, porque este é um organismo mundial que monitora este setor expondo estas estatísticas. Porém, se deve ressaltar que o Turismo MICE também inclui vários tipos de eventos além dos internacionais. Por exemplo, os eventos podem ser classificados segundo sua natureza, em: Eventos Internacionais, Eventos Nacionais com participação estrangeira, Eventos Nacionais, Eventos Multidestinos, e Eventos Itinerantes (Aguero, 2007). Salienta-se esta classificação, pois nela se observa uma 
oportunidade para pequenas e médias cidades tornarem-se destinos MICE de nível nacional, especialmente regional, movimentando fluxos de turismo interno no país.

Neste sentido, é preciso esclarecer alguns pontos relevantes para desenvolver esta atividade turística, definir quais critérios são utilizados pelos organizadores de eventos ao escolher uma cidade/local que receberá um evento (Crouch \& Louviere, 2004). Assim, com base nestas estas informações desenvolver os recursos e capacidades para uma inserção competitiva em Turismo MICE. Portanto, o principal objetivo deste artigo é apresentar uma revisão teórica conceitual de Turismo MICE, suas tipologias e seus determinantes de competitividade em nível de destino. Estes determinantes podem ser usados como critérios de ação para o planejamento estratégico voltado a desenvolver aptidão ao Turismo Meeting. Representando uma ferramenta gerencial que pode expressar indicadores de capacidade, qualidade, resultado e competitividade ( $\mathrm{Qu}, \mathrm{Li} \& \mathrm{Chu}, 2000)$. Secundariamente, se objetiva como forma de contextualizar esta temática, apresentar a cidade de Pelotas frente a estes determinantes de turismo MICE, considerando seu potencial como Destino MICE de eventos regionais, além das possibilidades de eventos nacionais e internacionais. Este artigo classificase como um estudo de caso, qualitativo, que utiliza uma revisão teórica e conceitual como base analítica.

A cidade de Pelotas situa-se no extremo sul do Estado do Rio Grande do Sul, sendo considerada uma cidade regional Instituto Brasileiro de Geografia e Estatística [IBGE] ( 2007) que recebe um grande fluxo de pessoas para negócios, compras, estudos e turismo, especialmente vindo de várias partes do Estado e de algumas cidades do MERCOSUL, tais como dos países Uruguai e Argentina.

\section{FUNDAMENTAÇÃO TEÓRICA}

\subsection{TURISMO MICE: CONCEITOS E TIPOLOGIAS}

Uma das modalidades turísticas que resulta de uma sub tipologia do turismo de negócios englobando as reuniões vinculadas a atividades laborais, profissionais ou associativas é conhecida pela palavra inglesa Meeting. Está sendo sintetizada na sigla MICE, que resume todos os tipos de reuniões: Meetings, Incentives, Conferencing, Exhibitions (Chim-Miki et al, 2013; Mair \& Jago, 2010; Monge \& Brandimarte, 2011;Weber \& Laudkin, 2005). Na literatura encontram-se algumas variações de associações a esta sigla, que 
algumas vezes associa „, $\mathrm{E}^{\mathrm{ee}}$ com eventos e „, $\mathrm{C}^{\mathrm{ee}}$ com convênios (Monge \& Brandimarte, 2011; Weber \& Laudkin, 2005).

O turismo MICE trata do fluxo de pessoas gerado por reuniões de negócios, congressos, convenções, viagens de incentivo, jornadas, encontros, simpósios, foros, seminários, cursos, etc... A grande maioria destes eventos ocorre em uma área urbana, portanto, está subárea do turismo de negócios fica abarcada pelo turismo Urbano, o qual também apresenta forte crescimento nos últimos anos (Ro \& Um, 2006; Wan, 2011). Segundo o Relatório URBANTUR (2012), o turismo urbano se apresenta como oportunidade para diversificar e minimizar a sazonalidade do tradicional turismo de "Sol e Praia" que em muitos casos está perdendo dinamismo devido à maturidade atingida no ciclo de vida do destino turístico (URBANTUR, 2012). Assim que, um forte contribuinte ao crescimento do turismo urbano vem do turismo MICE.

Vários autores destacam como vantagem para um destino desenvolver o turismo MICE como forma de diminuir a sazonalidade das outras modalidades de turismo, pois é comum estes eventos serem organizados em períodos de baixa temporada (Abbey \& Link, 1994; Janiskee, 1996; Labasse, 1984; Law, 1993; Lai, 2009; Monge \& Brandimarte, 2011; Oppermann, 1996; Ryan, Ryan, Smee \& Murphy, 1998; Ritche \& Beliveau, 1974; Ritche \& Crouch, 1998; Wan, 2011).

O turismo MICE além de oferecer possibilidades de minimizar a sazonalidade das outras modalidades de turismo também é apontado por outras vantagens. Entre as vantagens financeiras, está o fluxo turístico gerado e o fato de que o turista MICE apresenta um gasto diário maior no destino do que o turista de lazer (Labasse, 1984; Law, 1993). Também são apontadas vantagens não financeiras como a revitalização de áreas centrais, recuperação de bairros decadentes, melhoria de imagem da cidade e geração de um orgulho cívico entre os residentes (Getz, 2008; Hall, 1992;Law, 1987 ). Em termos de eventos internacionais, se devem incluir a melhoria de imagem do país, não somente como um destino turístico, mas como um local para se viver e investir (Crouch \& Ritchie, 1999), a divulgação da cultura local (Crouch \& Ritchie, 1999; Mistilis \& Dwyer, 1999), e as oportunidades de internacionalização de empresas locais (Meyer \& Skak, 2002).

Neste artigo, utilizaremos a nomenclatura Turismo MICE, e consideraremos a classificação dos eventos segundo Aguero (2007), que pode ser observada no quadro 1. Igualmente, esclarecemos que neste trabalho se adota a nomenclatura internacional, onde o setor MICE integra todos os setores que produzem e comercializam produtos e serviços, bem como a atuação dos profissionais liberais para estas atividades. Ou seja, todas as partes da 
Mice Tourism (Meetings, Incentives, Conferencing and Exhibitions) como gerador de turismo interno: analisando a cidade de Pelotas, RS

cadeia de valor que se forma para o desenvolvimento do turismo MICE, compõe o que internacionalmente se conhece por MICE Industry.

Quadro 1: Classificações dos eventos englobados no Turismo MICE

\begin{tabular}{|c|c|}
\hline \multirow{10}{*}{$\begin{array}{l}\text { Segundo o tipo de } \\
\text { evento }\end{array}$} & Congressos e Convenções \\
\hline & Conferências \\
\hline & Exposições e feiras \\
\hline & Simpósios e Jornadas \\
\hline & Seminários e Colóquios \\
\hline & Reuniões/Painéis/Debates/Mesas redondas \\
\hline & Assembleias \\
\hline & Festivais \\
\hline & Viagens de incentivo \\
\hline & Eventos virtuais \\
\hline \multirow{5}{*}{$\begin{array}{c}\text { Segundo a natureza } \\
\text { do evento }\end{array}$} & Internacionais \\
\hline & Nacionais com participação estrangeira \\
\hline & Nacionais \\
\hline & Multidestinos \\
\hline & Itinerantes \\
\hline \multirow[t]{2}{*}{ Segundo sua geração } & Organização própria \\
\hline & Sede Captada \\
\hline \multirow{3}{*}{ 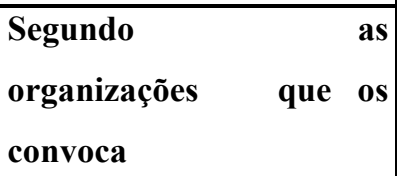 } & Governamentais \\
\hline & Não governamentais \\
\hline & Coorporativos \\
\hline \multirow{8}{*}{ Segundo o setor gerador } & Científicos-técnicos \\
\hline & Médicos \\
\hline & Agricultura e Meio Ambiente \\
\hline & Culturais \\
\hline & Educacionais \\
\hline & Jurídicos \\
\hline & Comerciais \\
\hline & Desportivos \\
\hline \multirow{5}{*}{$\begin{array}{l}\text { Segundo o tamanho ou } \\
\text { número de delegados } \\
\text { (participantes) }\end{array}$} & Mini eventos (entre 35 a 45 delegados) \\
\hline & Pequenos (entre 50 a 149 delegados) \\
\hline & Médios (entre 250 a 499 delegados) \\
\hline & Grandes (entre 500 a 2000 delegados) \\
\hline & Mega eventos (mais de 2000 delegados) \\
\hline \multirow[b]{2}{*}{ Segundo o objetivo } & Eventos Promocionais \\
\hline & Eventos Informativos \\
\hline
\end{tabular}




\begin{tabular}{|l|l|}
\hline \multirow{2}{*}{} & Eventos Formativo-didáticos \\
\cline { 2 - 2 } & Eventos de reforço de relações sociais \\
\cline { 2 - 2 } & Eventos de relações externas \\
\hline Eventos de relações internas
\end{tabular}

Fonte: Elaborado pelos autores, adaptado de Aguero (2007)

Normalmente, o desenvolvimento de um destino MICE envolve a existência de uma organização que atua na captação dos eventos, os chamados Convention Visitors Bureau [CVB]. O setor MICE se profissionalizou com a criação de associações, como por exemplo, a International Congress and Convention Association (ICCA), fundada em 1963, a Meeting Profesionals International [MPI], fundada em 1972, a International Special Events Society [ESES], fundada em 1987, e várias outras de nível internacional, nacional ou local.

O setor MICE movimenta muitos setores, os quais Rogers (2013) identificam como quatro principais elementos organizacionais e estruturais, a saber: Compradores, Fornecedores, Agências e intermediários e outras organizações (Figura 1). Outros pesquisadores identificam sete grupos interessados (stakeholders) no setor MICE, como sendo os Hospedeiros de convenções (destinos), Espaços e Instalações, Prestadores de serviço, Expositores, Participantes da Convenção, Operadores de Convenções, e Agências /CVB (Fenich, 2001; Kim ,Sun \& Kang, 2015) Esta rede de stakeholders do chamado setor MICE movimenta um grande número de produtos e serviços para a realização de um evento. Assim, um destino que deseja sediar um evento ou consagrar-se como Destino MICE deverá atuar sobre vários setores, para que em conjunto possam desenvolver esta modalidade de turismo.

Figura 1: Elementos organizacionais e estruturais do setor MICE

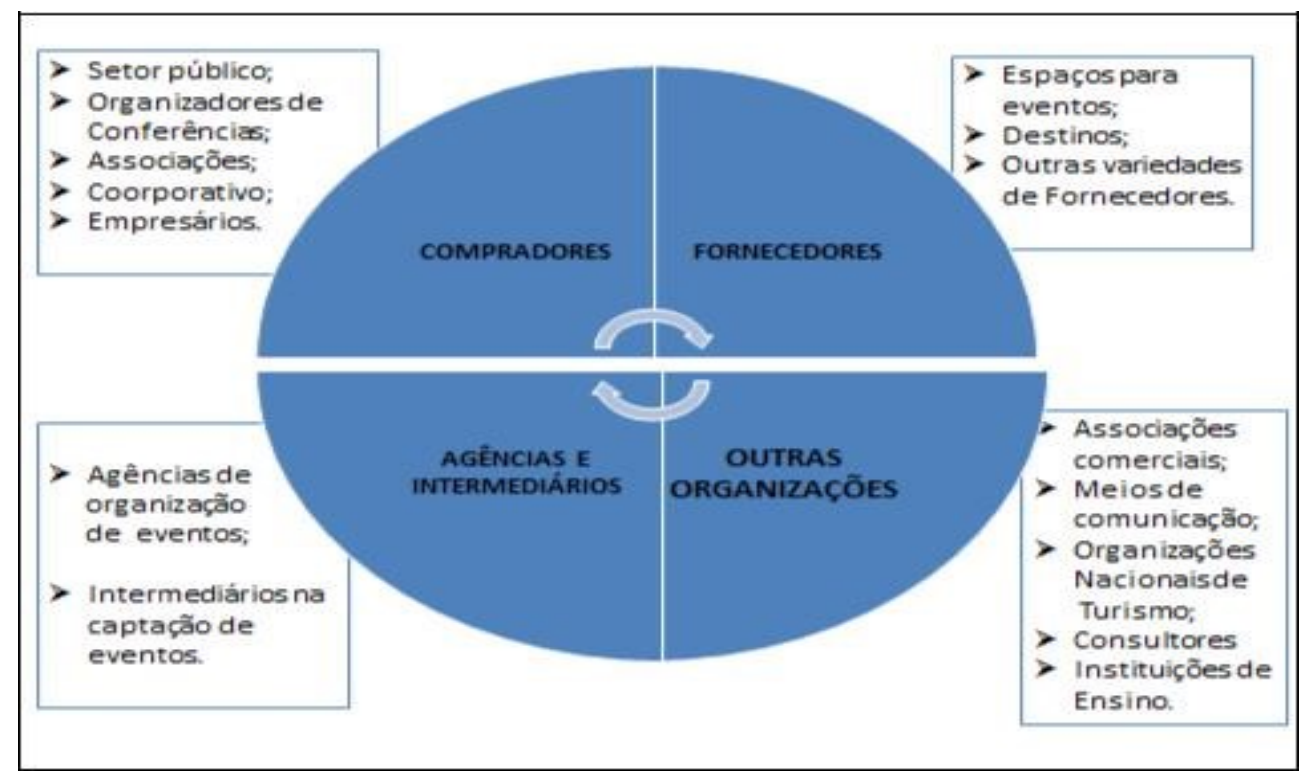

Fonte: Elaborado pelos autores desde uma adaptação de Rogers (2013) 
A importância de um destino possuir um CVB ou outra instituição de promoção é a captação e organização de eventos para o destino. Por outro lado, existem similares organizações que operam na captação dos destinos, ou seja, são contratadas para executar um evento e precisam escolher o local. Considerando estes dois ângulos, um destino turístico MICE possui três grupos de "clientes": a organização que contrata o evento, o organizador/realizador do evento e o participante do evento (usuário final). A ótica de análise principal destes três grupos de clientes é bastante diversa, portanto os critérios de decisão do local também, mas existem pontos de intersecção (Figura 2). Estes pontos representam o ápice de satisfação que o evento pode gerar nos três grupos, sendo as principais capacidades que um destino MICE deve centrar seus esforços para ser competitivo (Rogers, 2013).

Figura 2: Intersecção de interesses/critérios dos três principais clientes do turismo MICE (Destino MICE)

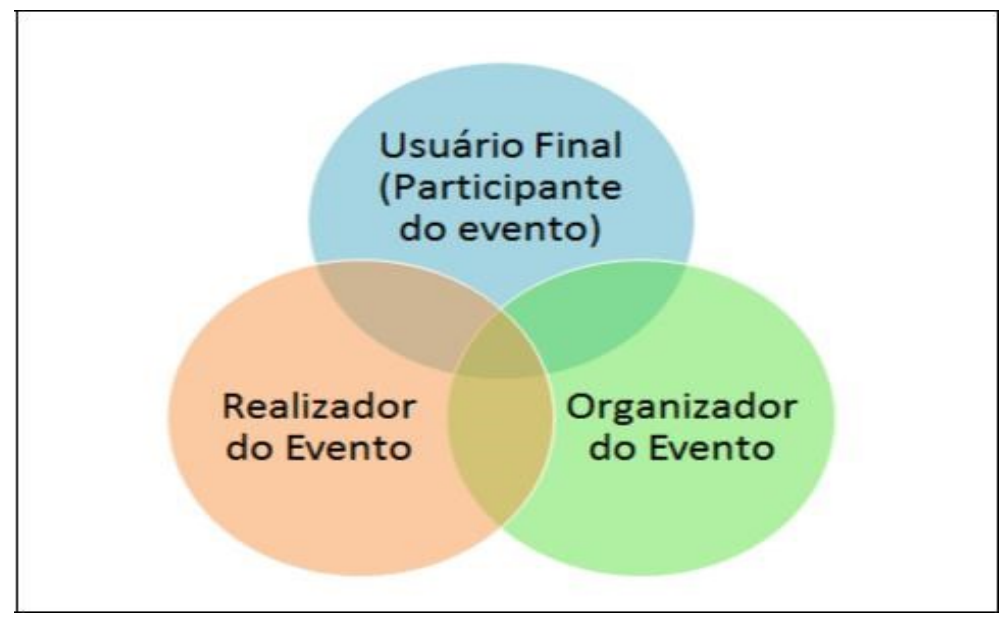

Fonte: Elaborado pelos autores

Um ponto relevante para a estruturação de um destino MICE é a formação da rede de empresas em torno do objetivo de desenvolver esta atividade, pois isto fundamenta o setor MICE local. A existência de uma governança turística ou o reconhecimento de um organismo centralizador, que considere uma gestão e planejamento participativo é a situação ideal para um destino MICE, pois um evento envolve uma série de atividades e serviços que são interrelacionados e interdependentes. Esta característica típica do sector de turismo em que os produtos/serviços são estritamente complementários frente aos turistas, representa um grande incentivo para a cooperação entre as diferentes empresas gerando com frequência uma organização em forma de governança (Della Corte \& Sciarelli, 2003; Della Corte \& Sciarelli, 2012; Rispoli \& Tamma, 1995). 
A governança surge a partir de que um sistema a reconhece a gestão integrada. Mayntz (2000) define como um novo estilo de governo, diferente do modelo de controle hierárquico, caracterizado por um maior grau de cooperação e interação entre os atores, formando uma rede público-privada de decisão. O conceito de governança tem sido aplicado a destinos turísticos pela dinâmica dos mesmos. Este conceito foi estabelecido pela Organização Mundial de Turismo [OMT] (2010), como:

Governança turística é uma prática de governo suscetível de medir, orientada a dirigir eficientemente o setor turístico nos distintos níveis de governo, mediante formas de coordenação e colaboração entre eles para realizar as metas compartidas pelas redes de atores que atuam no sector, objetivando obter soluções e oportunidades, baseados em acordos sustentados em uma relação de interdependências e responsabilidades compartidas. (OMT, 2010).

Desenvolver o turismo MICE a partir de uma governança centralizada ou de um CVB local com planejamento turístico participativo é uma maneira de profissionalizar este setor, mas focalizando em distribuir os benefícios da atividade turística de forma mais justa a todos os stakeholders (Buhalis, 2000).

No contexto interno e regional, as cidades médias e regionais apresentam características diferenciadas geradoras de turismo urbano. A funcionalidade dessas cidades, sua localização e inserção regional, as trocas comerciais com outros centros e a influência que exercem sobre o contexto regional são pontos que as definem como cidades (França, Pereira, Soares, \& Medeiros 2009), e que podem gerar uma oportunidade tornarem-se um Destino MICE. A localização é um dos mais salientados fatores de decisão para a escolha do lugar para a realização de um evento (Kim \& Kim, 2004). Especificamente sobre desenvolvimento de turismo MICE nacional, um estudo realizado na Austrália demostrou que a proximidade entre o lugar em que vivem os participantes da convenção e o lugar em que ocorre o evento, é um dos fatores significativos na decisão dos organizadores (Crouch \& Louviere, 2004). . O turismo interno inclui as atividades realizadas por um visitante residente no país de referência, como parte de uma viagem turística ou de uma viagem turística emissora (Nações Unidas, 2010). Neste sentido, a formação de um destino MICE regional gera um fluxo de turismo interno. 


\subsection{DETERMINANTES DA COMPETITIVIDADE TURÍSTICA MICE}

A competitividade de um destino MICE pode ser analisada pela perspectiva da demanda (organizadores, realizadores e participantes de eventos) ou pela perspectiva da oferta, promoção e desenvolvimento (destino). Em termos de competitividade turística geral, os autores mais proeminentes nesta temática são J.R. Brent Ritchie e Geoffrey I. Crouch, cujo modelo Calgary Model (1999), foi fundamentado em Teorias Porterianas (Porter, 1980), seguido de uma evolução apresentada pelos próprios autores em 2003: o Destination Competitiveness \& Sustainability Model. Estes dois modelos são base para muitos estudos sobre competividade. Porém, anterior à publicação que expos oficialmente o Calgary Model em 1999, estes mesmos autores haviam publicado um modelo de medição específico para o setor MICE. Crouch \& Ritchie (1998) publicaram um estudo em que identificaram nove categorias de fatores que determinam a eleição do local de convenção (Figura 3).

O General Conceptual Model of the Site Selection Process (Figura 3), apresenta condições prévias para um destino MICE que são relacionadas às condições associativas, ambientais e experiências passadas. Estes antecedentes levam aos atributos da competitividade MICE consideradas: Acessibilidade, Suporte local, Oportunidades extra conferência, Facilidades de acomodação, Facilidades de reunião, Informação, Lugares turísticos e outros critérios. De este conjunto, cinco passos ocorrem entre preparação e realização de uma convenção, formando um sistema que se retroalimenta (Ritchie \& Crouch, 1998). Este modelo foi base de uma aplicação empírica realizada pelo pesquisador Crouch e Louviere (2004) para verificar competitividade de Turismo Meetings Interno em Austrália. 
Figura 3: General Conceptual Model of the Site Selection Process

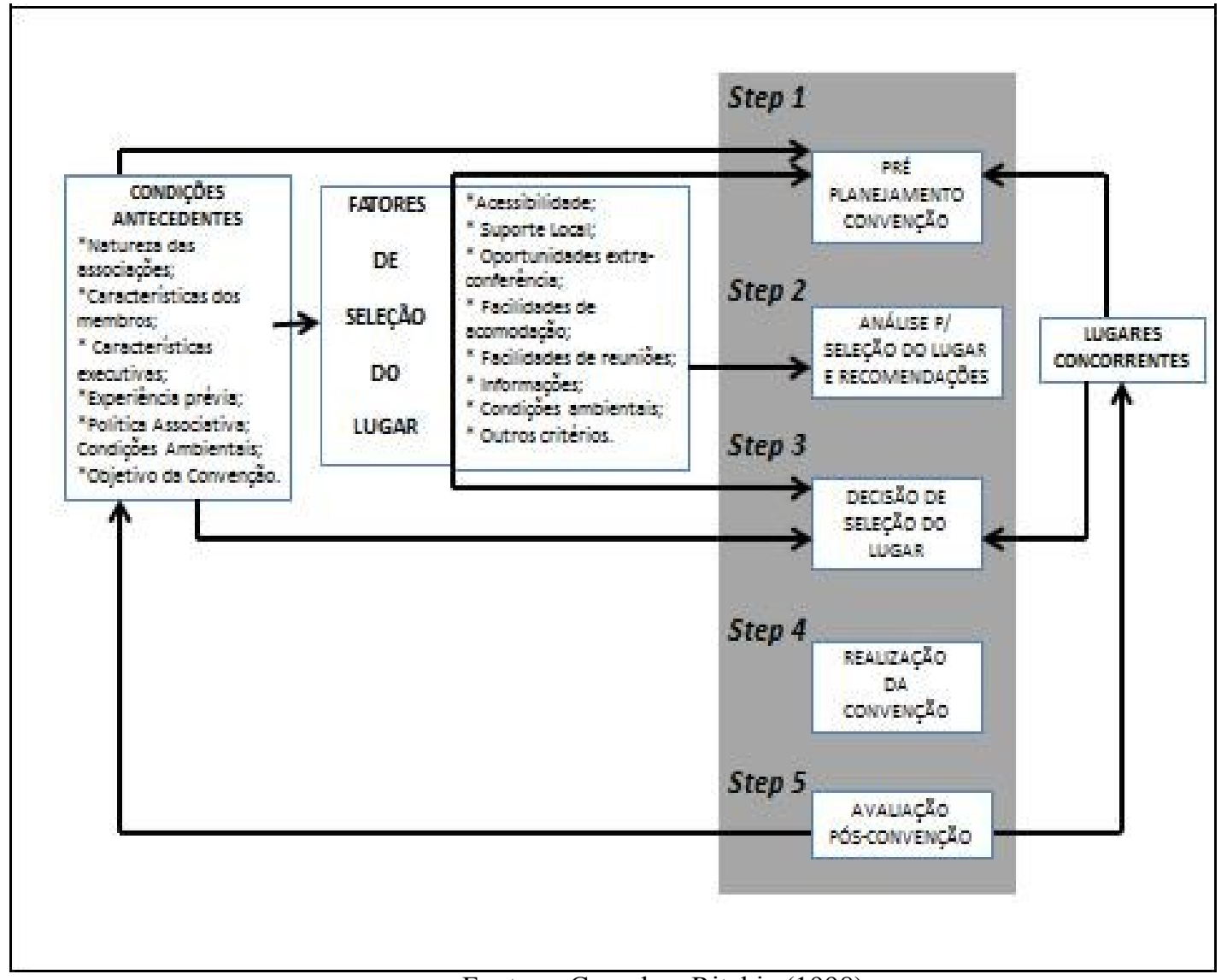

Fonte: Crouch e Ritchie (1998)

A continuação vários autores publicaram modelos ou critérios para o sucesso de um destino MICE. Assim, há uma variedade de enfoques para se chegar aos atributos de competitividade em turismo meetings, porém a maioria dos estudos coincide que algums item tem maior relevancia, entre eles: qualidade das salas de reuniões, custo, acessibilidade ao destino, e imagem do lugar (Law, 1993; Oppermann, 1996; Pearlman, 2008; Qu, Li \& Chu, 2000 ; Wong, 2011). No entanto, deve-se salientar que a importância dos atributos varia para cada tipo de reunião. Para complicar ainda mais este cenário, alguns autores apontam mudanças no panorama mundial em que alterações de rotas turísticas geram um novo atributo competitivo, que é a busca por celebrar reuniões em lugares novos (Callan \& Hoyes, 2000; Crouch \& Louviere ,2004; Leask \& Hood, 2001; Wong, 2011).

A Tabela 1 apresenta alguns autores que publicaram no período de 2008 a 2012, estudos em que se pode extrair indicadores para medir a competitividade MICE. Para uma melhor visualização, dividimos em atributos relacionados ao turismo em geral e atributos específicos do turismo MICE. 
Tabela 1: Variáveis/Indicadores de competitividade para Destinos MICE

\begin{tabular}{lrr}
\hline AUTOR/ANO & VARIÁVEIS/INDICADOR & VARIÁVEIS/INDICADORES \\
& ES GERAIS DO TURISMO & ESPECÍFICOS DO TURISMO MICE
\end{tabular}

Pearlman, D. Temperatura média estacional; Ofertas de salas de hotel; ADR, Ocupação e taxas de

(2008) Operações e embarques diários no impostos; Taxas para alugar automóveis; Assistência aeroporto. das reuniões de grupo; As taxas médias de trabalho do pessoal de apoio do centro de convenções; Gastos diretos dos assistentes às reuniões de grupo; Quantidade e metros quadrados de salas de reuniões, e salas de exposições; Projetos de ampliação de salas de exposições; Orçamento do CVB, pessoal, e o percentual de orçamento gasto em promoção do CVB.

McCartney, Imagem percebida do destino; Fatores externos: Papel do CVB e do governo local; G. Infraestrutura e logística; Associação local para suporte; Residentes locais para Oportunidades de atividades de ócio. suporte;

Fatores Internos: ciclo de convenções; Temática e objetivo das convenções; Alcance da associação; membros de apoio e fatores pessoais; financiamento.

Lai, L. S. Clima; Localização; Acessibilidade; Disponibilidade e qualidade dos espaços para (2009) Infraestrutura; Ambiente social; convenções; Acessibilidade a localização do evento; Lugares de interesse histórico; a Disponibilidade de equipamentos modernos cultural local; vistos de entrada; (audiovisual, equipes de conferência); Fornecimento Conexões internacionais; Preços de alimentos e bebidas com qualidade; Recursos competitivos; Disponibilidade das humanos competentes e professionais; Planificadores infraestruturas turísticas (hotéis, de convenções; Intérpretes; Pessoal de serviço centros comerciais, restaurantes, logístico; Recepcionistas; Pessoal para o refeitório; instalações de ócio); Atividades de Instalações para a equipe de gestão. ócio.

Wan, Y.K.P. Serviços de hotel; Opções de ócio;

(2011) Facilidade de acessibilidade- vistos; Boa localização e conexões com países do leste europeu; baixas taxas

Disponibilidade de hotel; Preços de pratos; Qualidade e quantidade de espaços para conferências; Modernos centros de exibição e convenção; Forte suporte governamental para o setor MICE; Modernas portuárias e de aeroportos; indústrias e serviços; População local que goste do Infraestrutura de transportes; turismo MICE; Possuir ativas associações para o Infraestrutura geral; Transportes desenvolvimento do turismo MICE; Qualidade e internos; Atrações; Marco de normas legal; Capacidade de abertura das fronteiras; Clima.

Tanford, S. Localização ( acessibilidade ao lugar, Montgomery, atratividade, serviços de hotel); Custos R. ( de transportes, de hotel); Visita aos Nelson, K.B. lugares circunvizinhos. Quantidade de recursos humanos para o setor MICE;

Programa (tópicos interessantes, reputação da convenção, programa da convenção, qualidade dos conferencistas); Preço da inscrição no evento; Possibilidade de visita a amigos/família; Busca de empregos; assistir a um amigo; Gerar negócios; promoção pessoal; oportunidades de network;

Fonte: Elaborado pelos autores

Observa-se pela Tabela 1 que o setor MICE é uma modalidade de turismo que exige uma estruturação local para receber estes eventos, principalmente uma carga de facilidades nos centros de eventos e uma prepração de equipes para trabalhar com este setor receptivo. Isto representa um desafio aos destinos turísticos, mas acima disto uma oportunidade. 


\section{METODOLOGIA}

A metodologia utilizada é de uma revisão teórica seguida de um estudo de caso. Este método de pesquisa é um dos mais utilizados pelos pesquisadores (Arzaluz, 2005), sendo uma análise do contexto real que utiliza fontes qualitativas ou quantitativas (Villarreal \& Landeta, 2010). Assim, neste trabalho é uma análise exploratória descritiva, baseada em dados secundários. Morra e Friedlander (2001) definem estudo de caso como um modelo de aprendizagem sobre uma situação complexa, que se baseia no entendimento compreensivo de um contexto, através da descrição e análise da situação que representa um conjunto de características dentro de uma realidade maior.

\subsection{CONTEXTO DE ANÁLISE}

A cidade de Pelotas situa-se no extremo sul do Estado do Rio Grande do Sul, as margens do Canal São Gonçalo que liga a Lagoa dos Patos e Lagoa Mirim, estando a $250 \mathrm{~km}$ da capital do Estado. É a terceira cidade mais populosa deste Estado, e considerada uma das cidades regionais (IBGE, 2007), fator que a coloca posicionada geograficamente e estrategicamente para ser um destino MICE regional.

De acordo com a Secretaria do Turismo do Rio Grande do Sul, Pelotas faz parte da Microrregião turística intitulada Costa Doce juntamente com outras 17 cidades das Regiões Centro-Sul e Sul do estado, e que estão organizadas através da Governança Regional da Agência de Desenvolvimento do Turismo na Costa Doce. Com relação ao Índice de Competitividade de Destinos Turísticos do MTur (2013) e SETUR (2013), Pelotas obteve um índice geral de 63,9 em 2013, obtendo um valor superior da média dos 29 municípios gaúchos de 56,8. Sua oferta turística é variada, possuindo condições de ofertar turismo de sol e praia nos meses de verão, turismo histórico e cultural e turismo rural / ecoturismo. Além disso, é um centro comercial e educacional regional, pois sua localização geográfica contribui para o fluxo de pessoas vindas das cidades vizinhas e do interior do estado, bem como das cidades fronteiriças dos países próximos ao sul do Brasil (Prefeitura Municipal de Pelotas, 2014; CVB Pelotas, 2014).

Atualmente a cidade se organiza turisticamente utilizando como estratégia de desenvolvimento uma governança turística liderada pelo Conselho Municipal de Turismo (COMTUR), reestruturado no ano de 2014, que coordena uma rede de stakeholders composta 
por: Universidades, Sistema S, ONG's, Agências de Viagens, Meios de Hospedagem, Representantes do Comércio, Setor de Alimentos e Bebidas, Representantes do Turismo Rural, Profissionais de Turismo, Setor de Esporte e Setor de Eventos (Prefeitura Municipal de Pelotas, 2014).

Este trabalho apresenta a cidade de Pelotas e seus atributos frente ao desafio de tornarse um destino MICE regional. Para isto, com base na literatura estabelecemos os determinantes principais para o desenvolvimento desta atividade a nível regional (Figura 04). Considerando estes determinantes mínimos buscou-se, desde uma perspectiva de demanda (usuários finais e organizadores de eventos), que dados encontravam-se disponíveis para analisar a cidade de Pelotas como candidata a sediar uma convenção ou evento regional. Portanto, verificou-se que indicadores de medida relacionados aos atributos de destino MICE o destino oferece ao tomador de decisão que está escolhendo o destino sede de seu evento.

Figura 04: Determinantes principais para o desenvolvimento de turismo MICE regional

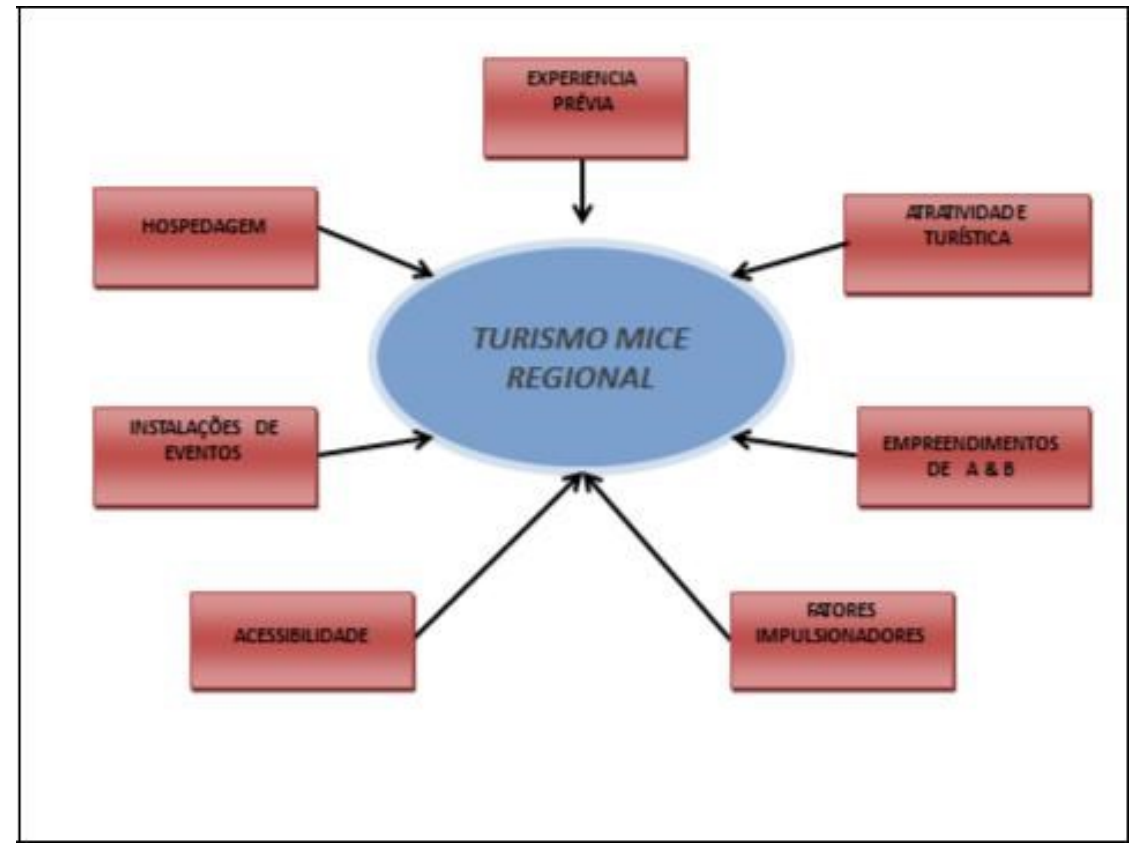

Fonte: Elaborado pelos autores

Considerando os sete determinantes apresentados na figura acima como condições mínimas para desenvolver um destino MICE a nível regional, coletaram-se dados para verificar a capacidade da cidade frente a estes determinantes. Os dados utilizados nesta análise foram obtidos através de três fontes de informações: (1) Coletados dos sites promocionais do turismo no destino, a saber: CVB Pelotas (www.pelotasconvention.com.br) e Prefeitura Municipal de Pelotas (www.pelotasturismo.com.br); (2) Coletados do inventário 
apresentado no Guia de Informações Turísticas, elaborado pela Prefeitura Municipal de Pelotas.

\section{ANÁLISE E DISCUSSÃO DOS RESULTADOS}

As tabelas a seguir mostram os indicadores de capacidade para os determinantes de turismo MICE regional da cidade de Pelotas, segundo a proposta de análise explicitada na metodologia e os fundamentos teóricos do turismo MICE. Foram considerados tanto estabelecimentos da cidade e da praia (Laranjal), pois está dentro da malha urbana da cidade, sendo comum a realização de eventos na orla da Lagoa dos Patos.

A dimensão competitiva que resulta no atributo Hospedagem na cidade de Pelotas foi verificada em termos de número total de camas e classificaram-se os empreendimentos hoteleiros segundo o número de leitos (Tabela 2). Wan (2011) considera entre os atributos necessários para a competitividade de um destino MICE a existência de disponibilidade de hotéis, enquanto o atributo preço é tratado por Tanford, Montgomery e Nelson. (2012). A oferta hoteleira da cidade é bem variada, totalizando 38 empreendimentos hoteleiros, entre os quais 15 estão categorizados como hotéis, seis como hospedagem alternativa, oito motéis e nove pousadas. Entre estes somente um empreendimento se pode considerar com maior porte, pois possui acima de 200 leitos, outros seis meios de hospedagem situam-se na faixa de $100 \mathrm{a}$ 199 leitos, e a grande maioria trata-se de empreendimentos hoteleiros com menor capacidade, possuindo menos de 100 leitos. Com relação ao custo de hospedagem na cidade há uma grande variação de preços, com hotéis econômicos de R\$ 50,00 a R\$ 160,00 a diária; hotéis executivos de $\mathrm{R} \$ 110,00$ a $\mathrm{R} \$ 360,00$ a diária, e hotéis considerados categoria Luxo de $\mathrm{R} \$$ 242,00 a 598,00 a diária. Segundo as informações dos sites verificou-se que a cidade possui alguns empreendimentos com modernas instalações hoteleiras.

Tabela 2: Capacidade das Instalações hoteleiras da cidade de Pelotas, RS

\section{HOSPEDAGEM}

\begin{tabular}{lr}
\hline N$^{\circ}$ de empreendimentos hoteleiros com mais de 200 leitos & 1 \\
N$^{\circ}$ de empreendimentos hoteleiros com 100 a 199 leitos & 6 \\
N$^{\circ}$ de empreendimentos hoteleiros com menos de 100 leitos & 31 \\
N $^{\circ}$ de camas totais & 2.299 \\
Disponibilidade de modernas instalações hoteleiras & Sim \\
\hline
\end{tabular}

Fonte: Elaborado pelos autores, informação extraída dos sites da Prefeitura Municipal e CVB Pelotas, 2014

Uma dimensão fundamental para o turismo MICE é representada pela capacidade de salas de reuniões, exibições e outros eventos (Lai, 2009; Pearlman, 2008; Wan, 2011). Na 
cidade de Pelotas, observou-se a oferta destas instalações, especialmente no site do CVB Pelotas e no relatório de informações turísticas da Prefeitura Municipal. O tipo de instalações, bem como a qualidade delas, varia muito de acordo com o objetivo do evento e público assistente. Assim, coletou-se a informação junto às fontes de maneira a facilitar uma visualização destes diferenciais (Tabela 3 ). A cidade possui vários espaços destinados a eventos, incluindo áreas campestres, pavilhões específicos para eventos de grande porte, clubes que incluem instalações para reuniões/eventos, instalações esportivas e até mesmo, os tradicionais CTGs (Centros de Tradições Gaúchas). Um CTG é o espaço criado para acolher as manifestações da tradição gaúcha, reunindo pessoas interessadas em divulgar e manter as tradições e o folclore desta cultura (Luvizotto, 2010), possuindo sedes próprias com condições para a realização de eventos. No entanto, nem todas as organizações informavam o número de pessoas que suas salas de eventos suportam, assim que a Tabela 3 não representa a oferta total da cidade, em termos de capacidade de pessoas.

A disponibilidade de serviços de equipamentos áudio visuais, prevista por Lai (2009) como importante para um destino MICE competitivo, bem como de serviços de tradução e de teleconferência não puderam ser avaliados, pois os sites não continham nada deste teor. Uma única empresa classificada no site como "serviços de Som, luz e palco" ofertava serviços, porém não apresentava lista de serviços específicos ou o tipo de equipamentos ofertados. Igualmente o custo de aluguel dos locais de convenção não está disponível on-line.

Tabela 3: Capacidade das Instalações de eventos da cidade de Pelotas, RS

\begin{tabular}{|c|c|c|}
\hline \multicolumn{2}{|c|}{ INSTALAÇÃO DE REUNIÕES/EXIBIÇÕES E OUTROS EVENTOS } & $\begin{array}{l}\text { Capacidade } \\
\text { Total(pessoas } \\
\text { sentadas) }\end{array}$ \\
\hline $\mathrm{N}^{\circ}$ de centros eventos (pavilhões) & 02 & $\overline{70.000}$ \\
\hline $\mathrm{N}^{\circ}$ de espaços abertos para eventos esportivos ou shows & 01 & 19.000 \\
\hline $\mathrm{N}^{\circ}$ de salas de convenções em hotéis & 07 & 2.230 \\
\hline $\mathrm{N}^{\circ}$ de salas em associações & 5 & 730 \\
\hline $\mathrm{N}^{\circ}$ de espaços para eventos em clubes e outros & 27 & 6.960 \\
\hline $\mathrm{N}^{\circ}$ de auditórios em centros de eventos & 3 & 1.150 \\
\hline $\mathrm{N}^{\circ}$ de salas/auditórios governamentais & 7 & 1.197 \\
\hline $\mathrm{N}^{\circ}$ de locais para eventos em Charqueadas & 3 & 412 \\
\hline Teatros em funcionamento & 2 & 1.439 \\
\hline Disponibilidade de serviços equipamentos áudio visuais & Não informado & \\
\hline Custo de aluguel dos locais de convenção & Não informado & \\
\hline Disponibilidade de serviços de tradução e de teleconferência & Não informado & \\
\hline Praça de alimentação em espaços destinados a eventos & 01 & 3000 \\
\hline
\end{tabular}


Empresas de sonorização de eventos

01

Fonte: Elaborado pelos autores, informação extraída dos sites da Prefeitura Municipal e CVB Pelotas, 2014

Quanto a dimensão Acessibilidade prevista como determinante competitivo tanto para destinos MICE (Lai, 2009; Tanford et al., 2012; Wong, 2011) como para competitividade turística em geral (Ritchie e Crouch, 2003), a análise das informações dos sites demonstra que a cidade possui boas conexões rodoviárias com outras cidades do interior (Tabela 4). Especialmente, com a capital do estado (Porto Alegre), existe regularidade de saídas a cada hora do dia. Também se destaca que existem linhas regulares de ônibus ligando Pelotas a outras cidades dos países vizinhos (Uruguai e Argentina). Por outro lado, o aeroporto possui baixa estrutura e poucos voos, não havendo infraestrutura para receber aeronaves de grande porte.

Tabela 4: Capacidade de acessibilidade para cidade de Pelotas, RS

\begin{tabular}{lc}
\hline \multicolumn{1}{c}{ ACESSIBILIDADE } & 01 \\
\hline Existência de aeroporto & Sim \\
Existência de boa comunicação rodoviária (rodovias de acesso) & Sim \\
Regularidade de transporte rodoviário coletivo ligando a cidade a outros municípios do Estado & Sim \\
Regularidade de transporte rodoviário coletivo ligando a capital do Estado & Sim \\
Regularidade de transporte rodoviário ligando a outros países próximos (Uruguai e Argentina) & Fonte: Elaborado pelos autores, informação extraída dos sites da Prefeitura Municipal e CVB Pelotas, 2014
\end{tabular}

A dimensão Experiência Prévia em meetings que Crouch \& Ritchie (1998) apontam em seu modelo conceitual da seleção de local para a realização de eventos, ficou demonstrada através do número de eventos que a cidade organiza, os quais no ano de 2014 contabilizaram uma média de 313 eventos variados (Tabela 5). Pelas informações do calendário de eventos anuais da Prefeitura Municipal de Pelotas e outras informações divulgadas no site do CVB observou-se que realizam eventos de abrangência local, regional e internacional, como é o caso do Festival de Música Internacional e do Festival de Jazz. Para o ano de 2015 o site da Prefeitura Municipal já apresenta 55 eventos cadastros entre os meses de janeiro a março. A cidade é bastante propícia ao desenvolvimento de eventos culturais, haja visto seu aspecto patrimonial e histórico, além de ser um polo comercial regional tradicional.

Tabela 5: Experiência prévia em eventos da cidade de Pelotas, RS

\begin{tabular}{lr}
\hline \multicolumn{1}{c}{ EXPERIÊNCIA PRÉVIA } & 313 \\
\hline Número médio de eventos na cidade & 04 \\
Número de empresas especializadas em turismo receptivo de eventos & 01 \\
Número de associações turísticas (CVB ou similar) & \\
\hline onte: Elaborado pelos autores, informação extraída dos sites da Prefeitura Municipal e CVB Pelotas, 2014
\end{tabular}


O serviço de Alimentos e Bebidas (A \& B) é um ponto importante na grande maioria dos eventos, constituindo-se uma dimensão nevrálgica, pois congrega três itens chaves: qualidade dos $\mathrm{A} \& \mathrm{~B}$, capacidade de atendimento a grande número de pessoas e preço adequado ao tipo de evento realizado (Bradley, Hall \& Harrison, 2002; Crouch \& Louviere, 2004). Os cardápios e tipo de empreendimentos de A \& B também variam de acordo com o público a ser atendido. Em Pelotas, um total de 164 empreendimentos de A \& B foram localizados nos sites pesquisados, sendo 88 restaurantes e pizzarias com grande variedade culinária que incluí gastronomia italiana, alemã, oriental, portuguesa, natural, árabe, francesa e colonial. Soma-se a esta oferta 24 bares e 52 cafés e doçarias, os quais alguns são bastante antigos e tradicionais da região (Tabela 6).

Identificou-se que é um ponto destacado na cidade de Pelotas a gastronomia local, e a capacidade de desenvolver um evento sustentável em A \& B, utilizando os produtos de produção própria, do tipo artesanais ou de agroindústrias rurais de pequenas propriedades agrícola, além dos produtos das grandes indústrias alimentícias da região. A cidade possui área rural nas proximidades com produção diversificada de hortifrutigranjeiros, pecuária e produção de bebidas, especialmente sucos e vinhos de produção própria. Além disso, é nacionalmente conhecida pela produção de doces artesanais, fato que contribuiu para nomear a região turística em que está inserida dentro do Programa de Roteirização do MTur (2013) como "Região Turística Costa Doce".

Porém, a informação de capacidade de atendimento de $\mathrm{A} \& \mathrm{~B}$ em número de pessoas/lugares ou mesas não está presente nos sites e documentos utilizados nesta amostragem. Os preços médios de A \& B variam muito de acordo com o cardápio solicitado e evento, desta forma, não consideramos este item nesta análise.

Tabela 6: Capacidade de fornecimento de A \& B da cidade de Pelotas, RS

\section{EMPREENDIMENTOS DE ALIMENTOS E BEBIDAS}

\begin{tabular}{lr}
\hline $\mathrm{N}^{\circ}$ de restaurantes e pizzarias & 88 \\
$\mathrm{~N}^{\circ}$ de bares e similares & 24 \\
$\mathrm{~N}^{\circ}$ de cafés, doçarias e lanchonetes & 52
\end{tabular}

Fonte: Elaborado pelos autores, informação extraída dos sites da Prefeitura Municipal e CVB Pelotas, 2014

McCartney (2008) indica as oportunidades de ócio como um fator de competitividade para destinos MICE, e neste mesmo sentido, Ritchie e Crouch (1998) apontam como um fator de decisão para a escolha do local a ser realizado o evento, as oportunidades extra conferência. Nos sites pesquisados, verificou-se que a cidade de Pelotas possui uma oferta 
turística que inclui sol e praia, pois esta as margens da Lagoa dos Patos, e seu entorno formado de várias Colônias rurais de imigrantes Italianos, Alemães e Pomeranos oferece um turismo experiencial gastronômico, cultural, histórico e paisagístico rural. Assim, sete roteiros turísticos diferentes são ofertados pelas agências de turismo receptivo local. Além disso, pelos históricos ciclos econômicos da cidade e região as chamadas "Charqueadas" são pontos turísticos marcantes. Trata-se de grandes propriedades rurais em que viveram os Barões da Carne Salgada. A condição climática é agradável e o centro histórico possui muitos prédios e casarios, além de uma série de museus (Tabela 7).

Tabela 7: Atratividade da cidade de Pelotas, RS

\begin{tabular}{|c|c|}
\hline ATRATIVIDADE TURÍSTICA & \\
\hline $\mathrm{N}^{\circ}$ de tipos de modalidades turísticas desenvolvidas no município & 07 \\
\hline $\mathrm{N}^{\circ}$ de roteiros turísticos receptivos ofertados nas agencias turísticas & 08 \\
\hline $\mathrm{N}^{\circ}$ de museus & 19 \\
\hline $\mathrm{N}^{\circ}$ de shopping centers & 01 \\
\hline Clima e natureza local - temperatura média anual & $17^{\circ} \mathrm{C}$ \\
\hline $\mathrm{N}^{\circ}$ de prédios históricos e casarios & 47 \\
\hline $\mathrm{N}^{\circ}$ de Charqueadas & 13 \\
\hline $\mathrm{N}^{\circ}$ de parques e áreas de natureza viva & 17 \\
\hline $\mathrm{N}^{\circ}$ de Postos de informação turística & 03 \\
\hline
\end{tabular}

Alguns itens impulsionadores do turismo MICE foram coletados das informações das webs sites pesquisados (Tabela 8). Estes itens são condições antecedentes, previstas no modelo decisório de Crouch e Ritchie (1998). A cidade desponta como um centro educacional e devido a sua localização geográfica, permite o acesso desde o interior do estado como das cidades fronteiriças de outros países. Este caráter educacional gera um número significante de eventos técnico-científicos que tende a contribuir para o Turismo Meeting.

Tabela 8: Fatores impulsionadores do turismo MICE da cidade de Pelotas, RS

\begin{tabular}{ll}
\hline \multicolumn{2}{c}{ FATORES IMPULSIONADORES } \\
\hline $\mathrm{N}^{\circ}$ de Universidades e centros de ensino Técnico & 09 \\
Localização geográfica & Boa \\
Existência/ $\mathrm{N}^{\circ}$ de cursos universitários e técnicos relacionados ao turismo e eventos & 03 \\
Existência de CVB local & 01 \\
$\mathrm{~N}^{\circ}$ de sites oficiais de promoção do destino & 03 \\
\hline
\end{tabular}

Fonte: Elaborado pelos autores, informação extraída dos sites da Prefeitura Municipal e CVB Pelotas, 2014 


\section{CONCLUSÕES}

O objetivo principal deste artigo foi apresentar uma breve revisão teórica sobre o Turismo MICE, suas tipologias e determinantes de competitividade, focalizando as oportunidades oferecidas por esta modalidade turística para as cidades que possuem um grau de polarização regional. Neste sentido, se realizou uma contextualização do setor na cidade de Pelotas, RS, Brasil. O turismo MICE se apresenta como um fator redutor de sazonalidade e um grande aliado do turismo urbano (URBANTUR, 2012). Este setor engloba uma série de produtos e serviços, a qual internacionalmente está sendo chamado de Indústria MICE. A variedade de tipos de eventos (Aguero, 2007) possibilita a formação de diferentes Destinos MICE, especialmente focados em um tipo de oferta de reuniões ou em uma abrangência geográfica, etc. As cidades regionais exercem uma influência no contexto regional e normalmente com uma posição geográfica que facilita o fluxo de turistas (Crouch \& Louviere, 2004; França, et al, 2009), portanto, esta condição associada a um gerenciamento públicoprivado que utilize uma governança turística participativa pode ser uma alavanca para o desenvolvimento de um destino MICE regional.

A atomização da oferta, típica do setor turístico (Baggio, 2008; Hjalager, 1999 ), é um ponto positivo para que o turismo Meeting se desenvolva de forma sustentável, inclusiva. No caso da cidade de Pelotas, as possibilidades de uso de produtos locais e o aproveitamento dos recursos humanos formados pelas universidades locais são pontos em que a cidade poderá apoiar um desenvolvimento econômico sustentável (Environmentally Sustainable Meeting Standards, APEX \& ASTM, 2012). Em termos de sua atratividade turística geral, a condição climática local é agradável para o turismo MICE, contrariamente ao desenvolvimento de turismo de Sol e Praia, pois a cidade possui poucos meses de verão. Este fato, associado ao patrimônio histórico-cultural do lugar favorece as apostas pelo turismo MICE desde uma polarização regional para a cidade de Pelotas.

Teórica e empiricamente uma definição dos determinantes de competitividade desta modalidade de turismo é um item que contribui para que as cidades planejem o uso de seus recursos ou o desenvolvimento dos atributos necessários a um destino MICE. A cidade de Pelotas anualmente já realiza um significativo número de eventos de alcance local e regional, assim como internacional, detendo uma experiência prévia neste setor. Os trabalhos de Fortin, Ritchie e Arsenault (1976) já indicavam que a experiência prévia é considerada um critério chave para os organizadores de eventos escolherem um destino para sediar seu evento. Além 
disso, a oferta de espaços destinados a eventos é variada, podendo atender a diferentes tipos de eventos/reuniões e exibições.

O ponto crítico está na estruturação e especialmente comunicação das capacidades da cidade como destino MICE que ainda precisam ser aprimoradas, já que as informações obtidas nos sites podem ser consideradas insuficientes para a tomada de decisão de eleger Pelotas como sede de um evento. Definitivamente, os itens relacionados a recursos tecnológicos para convenções não são incluídos nos sites pesquisados. Igualmente, se identificou falta de atualização dos dados. Por exemplo, um site indica a existência e capacidade para três teatros, no entanto um deles foi desativado há alguns anos por não apresentar condições de estruturais no prédio. Esta situação, no âmbito deste trabalho foi identificada através do conhecimento do pesquisador que vive nesta cidade.

No entanto, a cidade inclui em seu planejamento o turismo MICE, que somados a existência de um CVB local e de um Conselho de Turismo poderão gerar a estruturação de uma governança turística atuante em prol do desenvolvimento MICE. Assim, com base no trabalho empírico realizado e nas indicações teóricas apresentadas se recomenda algumas ações neste sentido, entre elas:

1. Realizar um inventário turístico atualizado de ativos/atributos e capacidades para o turismo MICE;

2. Identificar e classificar os principais agentes de oferta do setor MICE, mapeando a cadeia de valor formada;

3. Identificar e classificar os eventos habituais no município, bem como estabelecer o calendário de eventos e de ocupação dos recursos;

4. Elaborar um estudo analítico da demanda atual e perfil dos participantes de eventos;

5. Desenvolver um plano estratégico participativo com os stakeholders para fortalecer Pelotas como Destino MICE Regional;

6. Implantar ações em conjunto com as instituições de ensino para a capacitação de pessoas aptas a trabalhar nas diversas áreas do setor MICE;

7. Elaborar plano de marketing e campanhas de promoção de Pelotas como destino MICE, bem como estratégias de captação de novos eventos.

Resumindo, recomenda-se uma estratégia de trabalho em conjunto entre os stakeholders deste setor para que juntos tornem a cidade de Pelotas um destacado Destino MICE Regional, fonte de geração de empregos, renda e adequado aproveitamento dos recursos locais, aproximando-se a um conceito de Destino MICE sustentável. 


\section{REFERÊNCIAS}

Abbey, J. R. \& Link, C. K. (1994). The convention and meetings sector its operation and research needs. En Ritchie, J R B \& Goeldner, C R (eds.), Travel, Tourism, and hospitality Research (2a. ed.). (pp.273-284). New York: Wiley.

Agüero, M. G. (2007). Definiciones y tendencias del turismo de eventos. Contribuciones a la Economía, 82,

American Society of Association Executives (ASAE). (1992). Association meeting trends. Washington: ASAE

APEX/ASTM. Environmentally Sustainable Meeting Standards (2012). Convention Industry Council. Accepted Practices Exchange (APEX) and American Society of Testing and Materials(ASTM). Recuperado em 05 de novembro, 2014, de www.conventionindustry.org/Standards Practices/APEXASTM.aspx.

Arzaluz S. (2005). La utilización del estudio de caso en el análisis local. Región y Sociedad, . $32,107-144$.

Baggio, R. (2008). Network analysis of a tourism destination (Unpublished doctoral dissertation). School of Tourism, The University of Queensland, Brisbane

Bradley, A., Hall, T., \& Harrison, M. (2002). Selling cities: promoting new images for meetings tourism. Cities, 19 (1), 61-70.

Buhalis, D. (2000). Marketing the Competitive Destination of the Future. Tourism Management, 21(1), 97-116.

Brasil, Ministério do Turismo. (2013). Índice de Competitividade do Turismo Nacional: Destinos Indutores do Desenvolvimento Turístico Regional. Relatório Brasil, 2013 e 2014. Brasília: Ministério do Turismo

Callan, R. J. \& Hoyes, M. K. (2000). A Preliminary Assessment of the Function and Conference Service Product At a UK Stately Home. Tourism Management, 21(6), 571-581

Chim-Miki, A. F., Zuñiga-Collazos, A., Gandâra, J.G.G. \& Medina-Muñoz, D.R. (2013). La variable Competitividad en Meeting Tourism: una visión general de la actualidad. Escenarios: Empresa y Territórios, 2, 131-154.

Choi, J. \& Boger, C. A. (1998). Factors Influencing State and Regional Assocation"es Meeting Site. Advances in Hospitality and Tourism Research, 3. 577-584.

Convention \& Visitors Bureaux .(2014). CVB Pelotas. Recuperado em 10 de janeiro, 2015, de www.pelotasconvention.com.br 
Crouch, G. I., \& Ritchie, J. R. B. (1998). Convention site selection research: a review, conceptual model, and propositional framework. In Journal of Convention \& Exhibition Management 1( 1), pp. 49-69.

Crouch, G. I. \& Ritchie, J. R. B. (1999). Tourism Competitiveness, and societal prosperity. Journal of Business Research, 44 (3), 137-152.

Crouch, G. I., \& Louviere, J. J. (2004). The determinants of convention site selection: A logistic choice model from experimental data. Journal of Travel Research, 43 (2), 118-130.

Della Corte, V. \& Sciarelli, M. (2012). Can Coopetition be source of competitive advantage for strategic networks? Corporate Ownership \& Control, 10(1),363-379.

Della Corte V. \& Sciarelli M. (2003). "Evoluzione del marketing nella filiera turistica: Il ruolo dell "enformation \& Communication Technology", in J., Andreani \& U., Collesei . Atti del Terzo Congresso Internazionale sulle Tendenze di Marketing, Venice.

Dwyer, L., Mistilis, N., Forsyth, P. \& Prasada, R. (2001). International price competitiveness of Australia"e s MICE industry. International Journal of Tourism Research, 3(2), 123-139.

Fenich, G. (2001). Towards a Conceptual Framework for Assessing Community Attractiveness for Conventions. Journal of Convention \& Exhibition Management, 3 (1). $45-$ 64.

Monge, F., \& Brandimarte, P. (2011). Mice tourism in piedmont: economic perspective and quantitative analysis of customer satisfaction. Tourisms: an international multidisciplinary journal of tourism, 6 (1), 213-220.

Fortin, P. A., Ritchie, J. R. B. \& Arsenault. J. (1976). Study of the Decision Process of North American Associations Concerning the Choice Convention Site. Quebec: Laval University.

França, I. S., Pereira, A. M., Soares, B. R. \& Medeiros, D.L. (2009). Cidade Média, polarização regional e setor de educação superior: Estudos de Montes Claros, no norte de Minas Gerais. Revista Formação, 16 (2), 52-70

Getz, D. (2008). Event Tourism: Definition, evolution, and research. Tourism Management, 29(3), 403-428.

Go, F. \& Zhang, W. (1997). Applying Importance-Performance Analysis to Beijing as An International Meeting Destination. Journal of Travel Research, 35 (4), 42-49.

Governo do Estado do Rio Grande do Sul, SETUR. (2013). Secretária do Turismo. Índice de Competitividade: Destinos Turísticos do Rio Grande do Sul. RS.

Hall, C. M. (1992). Hallmark Tourist Events: Impacts, Management and Planning. London: Belhaven.

Hjalager, A.M. (1999). Tourism destinations and the concept of industrial districts. Paper presented at ERSA Conference, Dublin, Ireland. 
Instituto Brasileiro de Geografia e Estatística. (2007). Região de Influência das Cidades REGIC. Ed. 2007.IBGE

International Association Meeting Market. (2013). A Modern History of International Association Meeting. Statistics Reports 1963-2013. ICCA.

International Special Events Society.(2014). International Special Events Society .(ESES).

Recuperado em 10 de novembro, 2014, de http://www.ileahub.com/ilea-landing

Janiskee, R. (1996). The temporal distribution of America ${ }^{\text {ee }}$ community festivals. Festival Management and Event Tourism, 3 (3), 29-137.

Kim, W. G., \& Kim, H. C. (2004). The analysis of Seoul as an international convention destination. In Journal of Convention \& Exhibition Managemen, 5 (2), 69-87.

Kim, S.S., Sun, H.L \& Kang, N. (2015). Meeting Plannerse Competency, Motivation, and Benefits: The Case of Korea. Journal of Convention \& Event Tourism, 16 (1), 61-89.

Labasse, J. (1984). Les congrès, activité tertiaire de vi lles privilégiées. Annales de géographie, 93 (520), 688-703.

Lai, L. S. (2009). A Competitiveness Analysis of the Convention Tourism of China Special Administrative Region. World Academy of Science, Engineering and Technology, 60, 600-605

Law, C. M (1987). Conference and exhibition tourism. Built Environment, 13 (2), 85-95.

Law, C. M. (1993). Urban tourism. Attracting visitors to large cities. London: Mansell.

Leask, A. \& Hood, G. (2001). Unusual Venues as Conference Facilitites. Journal of Convention \& Exhibition Management, 2 (4), 37-63.

Luvizotto, CK. (2010). As tradições gaúchas e sua racionalização na modernidade tardia.(p.140) São Paulo: EdUNESP.

Mair, J. \& Jago, L. (2010). The development of a conceptual model of greening in the business events tourism sector. Journal of Sustainable Tourism, 18 (1), 77-94.

Mayntz, R. (2000). Nuevos Desafíos de la Teoría de Governance. Instituciones y Desarrollo, 7, 35-51.

McCartney, G. (2008). The CAT (casino tourism) and the MICE (meetings, incentives, conventions, exhibitions): Key development considerations for the convention and exhibition industry in Macao. Journal of Convention \& Event Tourism, 9 (4), 293-308.

Meeting Profesionals International.(2014). Meeting Profesionals International(MPI). Recuperado em 04 de novembro, 2014 de http://www.mpiweb.org/ 
Meyer, K. \& Skak, A. (2002). Networks, Serendipity and SME Entry into Eastern Europe. European Management Journal, 20 (2), 179-188.

Ministério do Turismo. (2012). Anuário Estatístico de Turismo, Ano base 2011. Secretaria Nacional de Politicas de Turismo (Vol.39). Brasília. MTur.

Ministério do Turismo. (2013). Programa de Regionalização do Turismo. Secretaria Nacional de Políticas de Turismo. Brasília: MTur.

Mistilis, N. \& Dwyer, L. (1999). Tourism gateways and regional economies: the distributional impacts of MICE. International Journal of Tourism Research, 1(6), 441-457

Monge, F. \& Brandimarte, P. (2011). MICE Tourism in Piedmont: Economic Perspective and Quantitative Analysis of Customer Satisfaction. Tourisms: An International Multidisciplinary Journal of Tourism, 6 (1), 213-220.

Morra, L.G. \& Friedlander, A.C. (2001). Evaluaciones mediante estudios de caso. Banco Mundial, Washington D.C.

Nações Unidas. (2010). International Recommendations for Tourism Statistics 2008, New York.

Organización Mundial de Turismo-OMT. (2010). Proyecto Gobernanza para el Sector Turístico - Informe Ejecutivo. Madrid.

Oppermann, M. (1994). Modeling convention location choice and participation decision making process. Aix-en-Provence: Centre des Hautes Etudes Touristiques.

Oppermann, M. (1996). Convention Destination Images: Analysis of Association Meeting Planners ${ }^{\text {ee }}$ Perception. Tourism Management, 17 (3), 175-182.

Oppermann, M., \& Chon, K. S. (1997). Convention participation decision-making process. Annals of tourism Research, 24 (1), 178-191.

Pearlman, D. (2008). Key Performance Indicators of the MICE Industry and the Top 25 United States and Canadian CVBs. Journal of Convention \& Event Tourism, 9 (2), 95-118.

Porter, M.E. (1980). Competitive Strategy: Techniques for Analyzing Industry and Competitors. New York: The Free Press.

Prefeitura Municipal de Pelotas. (2014). Guia de Informações Turísticas. Recuperado em 10 janeiro, 2015, de www.pelotasturismo.com.br

Qu, H., Li,L. \& Chu,G.K.T. (2000). The comparative analysis of Hong Kong as an international conference destination in Southeast Asia. Tourism Management, 21(6), 643-648.

Rispoli M. \& Tamma M. (1995). Le Risposte Strategiche alla Complessità: le forme di offerta dei prodotti alberghieri, Giappichelli, Torino. 
Ritchie, J. R. B. (1984). Assessing the impacts of hallmark events: Conceptual and research issues. Journal of Travel Research, 23 (1), 2-11.

Ritchie, J. R. B. \& Beliveau, D. (1974). Hallmark events: An evaluation of a stratewgic response to seasonality in the travel market. Journal of Travel Research, 13(2),14-20

Ritchie, J.R.B. \& Crouch, G.I. (2003), The Competitive Destination: A Sustainable Tourism Perspective, CABI. Publishing, Wallingford, UK.

Ro, Y. \& Um, S. (2006). Canonical Correlation Analysis on Importance Ratings between the Host Country Evaluation Attributes and the Convention Service Evaluation Attributes. International Journal of Tourism Sciences, 6 (1), 79-93.

Rogers, T. (2013). Conference and conventions: A global industry, (3rd ed). New York, NY: Routledge.

Ryan, C., Smee, A., Murphy, S. \& Getz, D. (1998). New Zealand events: A temporal and regional analysis. Festival Management and Event Tourism, 5 (1-2), 71-83.

Spiller, J., Weber, K., \& Chon, K. S. (2002). History of convention tourism. In Convention tourism: International research and industry perspectives (pp. 3-20). New York: Haworth Hospitality Press.

Tanford, S., Montgomery, R., \& Nelson, K. B. (2012). Factors that Influence Attendance, Satisfaction, and Loyalty for Conventions. Journal of Convention \& Event Tourism, 13(4), 290-318.

Urbantur. (2012). Monitor de Competitividad Turística de los Destinos Urbanos Españoles. Exceltur, Ed. Mayo, 2013. Urbantur.

Villareal, O. \& Landeta, J. (2010). El estudio de casos como metodología de investigación científica en dirección y economía de la empresa. Una aplicación a la internacionalización. Investigaciones Europeas de Dirección y Economía de la Empresa, 16 (3), 31-52.

Wan, Y. K. P. (2011). Assessing the Strengths and Weaknesses of Macao as an Attractive Meeting and Convention Destination: Perspectives of Key Informants. Journal of Convention \& Event Tourism, 12(2), 129-151.

Wong, I. A. (2011). Using Destination Attributes to Promote Event Travel: The Case of Macau. Journal of Convention \& Event Tourism, 12(4), 241-252.

Weber, K. (2001). Meeting Planners ${ }^{\text {ee }}$ Use and Evaluation of Convention and Visitor Bureaus. Tourism Management, 22(6), 599-606.

Weber, K. \& Ladkin, A. (2005). Trends affecting the convention industry in the 21 st Century. Journal of Convention \& Event Tourism, 6(4). pp. 47-63.

Zelinsky, W. (1994). Conventionland USA: The geography of the latterday. Annals of the Association of American Geographers, 84, 68-86. 